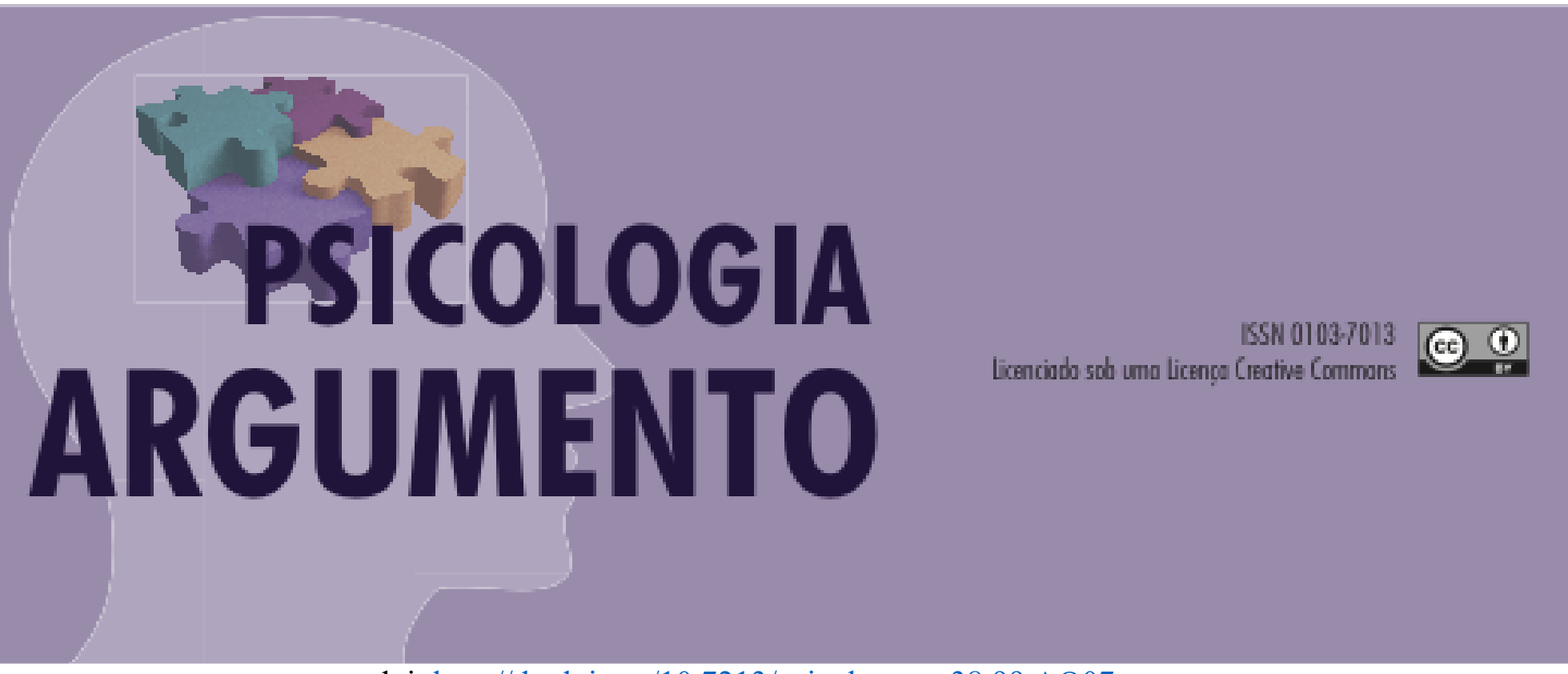

doi: http://dx.doi.org/10.7213/psicolargum.38.99.AO07

\title{
Interlocuções entre os discursos médico e psicanalítico: por uma leitura sobre a desmedicalização em psiquiatria
}

\author{
Interlocutions between medical and psychoanalytic discourses: a reading on \\ demedicalization in psychiatry
}

Interlocuciones entre discursos médicos y psicoanaliticos: para una lectura sobre desmedicalización en psiquiatría

Luciana Jaramillo Caruso de Azevedo

Doutoranda em Psicologia Clínica (PUC-Rio) E-mail: lucianajaramillo@msn.com orcid.org/0000-0001-5627-2636

\begin{abstract}
Resumo
A tensão existente entre a medicina e a psicanálise mobiliza profícuas discussões. A psicanálise se destaca por ser uma área do conhecimento que oferece dispositivos significativos para fazer frente à medicalização desenfreada, possibilitando a escuta de novas formas de subjetividade na cena contemporânea. $\mathrm{O}$ presente estudo propõe uma reflexão acerca dos discursos médico e psicanalítico no que se refere ao processo de medicalização. As noções de sintoma, diagnóstico e sofrimento se configuram como dispositivos balizadores desta discussão. O sintoma psicanalítico enquanto portador de sentido e significação carrega consigo a verdade do sujeito. Diferentemente da medicina onde se tenta abolir o sintoma, a psicanálise compreende o sintoma como um significante que aponta para a estrutura de linguagem inconsciente. Em função disso, faz-se necessário um constante aprofundamento da dialética entre os saberes médico e psicanalítico com o intuito de se construir uma ética do cuidado que ultrapasse a perspectiva biologizante/medicalizante.
\end{abstract}

Palavras-chave: medicalização, sofrimento, sintoma, diagnóstico, psicanálise. 


\begin{abstract}
The tension between medicine and psychoanalysis mobilizes fruitful discussions. Psychoanalysis stands out for being an area of knowledge that offers significant devices to cope with unbridled medicalization, enabling the listening of new forms of subjectivity in the contemporary scene. This study proposes a reflection on the medical and psychoanalytical discourses regarding the medicalization process. The notions of symptom, diagnosis and suffering are configured as guiding devices of this discussion. The psychoanalytic symptom as bearer of meaning and meaning carries with it the truth of the subject. Unlike medicine where attempts are made to abolish the symptom, psychoanalysis understands the symptom as a signifier that points to the unconscious language structure. Because of this, a constant deepening of the dialectic between the medical and psychoanalytical knowledge is necessary.
\end{abstract}

Keywords: Medicalization, suffering, psychoanalysis.

\title{
Resumen
}

La tensión entre la medicina y el psicoanálisis moviliza discusiones fructíferas. El psicoanálisis destaca por ser un área de conocimiento que ofrece importantes dispositivos para hacer frente a la medicalización desenfrenada, lo que permite escuchar nuevas formas de subjetividad en la escena contemporánea. Este estudio propone una reflexión sobre los discursos médicos y psicoanalíticos sobre el proceso de medicalización. Las nociones de síntomas, diagnóstico y sufrimiento se configuran como dispositivos de guía de esta discusión. El síntoma psicoanalítico como portador de significado y significado conlleva la verdad del sujeto. A diferencia de la medicina, donde se intenta abolir el síntoma, el psicoanálisis entiende el síntoma como un significante que apunta a la estructura del lenguaje inconsciente. Debido a esto, es necesaria una profundización constante de la dialéctica entre el conocimiento médico y el psicoanalítico.

Palabras clave: medicalización, sufrimiento, síntoma, diagnóstico, psicoanálisis.

\section{Introdução}

Neste ensaio propomos uma discussão acerca dos discursos médico psiquiátrico e psicanalítico no que se refere ao processo de medicalização, especialmente no tocante às noções de sintoma, diagnóstico e sofrimento. A partir da década de 1950, duas mudanças no pensamento psiquiátrico contribuíram significativamente para a expansão cultural da medicalização: a criação do DSM-I, em 1952, que elencou sintomas e formas diagnósticas e sofreu sucessivas reformulações; a descoberta do primeiro neuroléptico, a clorpromazina.

Os psicotrópicos modificaram a paisagem da loucura, esvaziaram os manicômios, substituindo a camisa-de-força e os tratamentos de choque pela redoma medicamentosa. Embora estes psicofármacos não curem as denominadas doenças mentais, elas revolucionaram as representações do psiquismo e fabricaram um novo homem. Receitado tanto por clínicos gerais quanto pelos especialistas em psicopatologia, os psicotrópicos têm como efeito normalizar comportamentos e eliminar os sintomas mais dolorosos do 
sofrimento psíquico sem lhes buscar significação. Assim, a clínica na atualidade, com os impasses que se delineiam em seu campo, se impõe como um problema em pauta.

No que tange a essa problemática, Birman (2018) ressalta a articulação entre os discursos provenientes da psiquiatria biológica, docognitivismo e da terapia comportamental procurou desarticular o dispositivo da clínica do psíquico, na medida em que os registros do sujeito e da singularidade são colocados em questão no campo terapêutico oriundo de tais discursos. É preciso considerar que esses discursos se inscrevem num paradigma naturalista de cientificidade, fundados nos discursos teóricos da biologia e das neurociências. Esses diferentes discursos se articulam e se conjugam na série de reconfigurações produzidas do DSM (Manual diagnóstico e estatístico de transtornos mentais).

Consubstanciando o pensamento crítico de Birman, Tenório (2016) ratifica que a intenção declarada das modificações em torno das classificações psiquiátricas foi estabelecer o maior consenso possível para qualquer que fosse a escola adotada pelo psiquiatra. Para tanto, o DSM e, posteriormente, a CID (Classificação Estatística Internacional de Doenças e Problemas Relacionados com a Saúde) proclamaram-se "ateóricos", excluindo as categorias que implicavam pressupostos psicodinâmicos e pretenderam basear a classificação exclusivamente em sintomas que pudessem ser empiricamente observados, descritos e quantificados. Tenório (2016) salienta a mudança paradigmática que ocorreu na formulação do DSM-III, quando o discurso médico da medicina baseada em evidências assolou os manuais psiquiátricos. Contudo, nota-se como efeito dessas mudanças a supressão da referência à psicanálise e outras teorias psicodinâmicas que eram encontradas nas versões anteriores do DSM. O apoio exclusivo nos sinais e sintomas para a descrição de psicopatologias favoreceu a ênfase cada vez maior na ação farmacológica no tratamento. A virada realizada a partir do DSM III é um ponto central para esta discussão.

Com efeito, também é importante notar que uma transformação fundamental também ocorreu na economia simbólica da lei moral, ela passou a ser regulada pelo imperativo do sujeito de atingir a condição de felicidade. No entanto, se a felicidade se transformou em um imperativo irrepreensível, isso se deve à democratização do espaço social que concedeu a todos a pretensão de igualdade. Em uma sociedade supostamente democrática, a igualdade se transformou em um dos seus ideais primordiais e um dos alicerces da cidadania. Por isso, a aspiração à felicidade passou a ser pleiteada como algo 
da ordem do direito. O mandato de ser feliz, "custe o que custar", se coloca hoje efetivamente como uma demanda inequívoca. Em decorrência disso, a depressão passou a se impor como uma das maiores modalidades de sofrimento psíquico, pois evidencia o fracasso performático do sujeito (Birman, 2010).

É interessante destacar uma questão incontornável proposta por Freitas e Amarante (2017): os fenômenos psicopatológicos não existem sem os constructos psiquiátricos? Como estes constructos são forjados e qual a sua relação com a cultura?

Segundo o pensamento do filósofo francês Gilles Lipovetsky (1989) sobre o universo do espetáculo, as idealizações não cessam de ir ao encontro da vida. Para Lipovetsky (1989), existe uma cultura de massa amplamente difundida e destinada a satisfazer a necessidade de evasão dos indivíduos, cujos efeitos de longo prazo são diversos e atingem todas as camadas sociais. Esta cultura de massa teve como função histórica determinante a reorientação das atitudes individuais e coletivas, bem como a difusão de novos padrões de vida, seguindo novos referentes ideológicos e modelos existenciais. A cultura de massa foi um vetor essencial do individualismo contemporâneo, sua obra hipnótica apenas sacraliza o indivíduo em ficção, engrandece a felicidade tornando irreais as existências concretas. Para o autor, este tipo de cultura faz viver por procuração imaginária um indivíduo sonambúlico, despossuído de si mesmo pelas figuras encantadas no imaginário.

Nesse panorama, observamos que uma série de mal-estares humanos vem sofrendo um deslocamento progressivo de sentido, por vezes servindo para forjar novos quadros psicopatológicos. Freitas e Amarante (2017) observam que as categorias de diagnóstico do DSM podem ser melhor analisadas quando as consideramos constructos, isto é, produtos de processos de construção social da realidade. Assim, este ensaio teórico visa a problematizar as tensões existentes entre os discursos médico e psicanalítico no que se refere ao processo de medicalização. Para realizar esta proposta, as noções de sofrimento, sintoma e diagnóstico se configuram como dispositivos balizadores desta discussão.

\section{A medicalização e a difusão do discurso médico}

Com o avanço das neurociências e a disseminação cultural do discurso médico, a linguagem para designar o mal-estar do qual o sujeito padece foi atravessada pelo 
materialismo biológico, desconsiderando outros aspectos relevantes da existência humana.

Data de 1952 a primeira sintetização de um psicofármaco utilizado em tratamentos psiquiátricos. Desde então, a indústria farmacêutica investe massivamente, ano após ano, cada vez mais recursos no estabelecimento de pesquisas na área da psicofarmacologia e investe grande parcela de recursos no marketing de novas drogas. Há uma assustadora inversão na construção da lógica diagnóstica contemporânea, posto que o remédio participa da nomeação do próprio transtorno. Não há mais uma etiologia e uma historicidade a serem consideradas, pois a verdade do sintoma/transtorno está no funcionamento bioquímico, e os efeitos da medicação dão validade a um ou outro diagnóstico (Guarido, 2007).

Se por um lado, o conceito de medicalização refere-se à expansão da jurisdição da medicina para novos domínios, principalmente àqueles que dizem respeito a problemas considerados de ordem moral, legal ou criminal. E a medicina transformou-se num dispositivo de controle social, assumindo a função de regulação que antes era exercida pela Igreja e pelo judiciário (Brandão, 2012). Por outro, é importante destacar que a medicalização não se restringe especificamente ao médico no exercício legítimo de suas atribuições (ainda que alguns se rendam à uma versão da medicina baseada na lógica de mercado), mas na propagação do saber médico para além das práticas da medicina.

Nesse sentido, pensamos que os discursos e práticas da medicina se difundem e penetram no tecido social, os indivíduos e a sociedade vão sendo produzidos por eles e se moldando ao saber médico. O próprio viver passou a ser capturado pelo discurso médico, quase toda tristeza passou a ser vivenciada como sinal de depressão (Aguiar, 2004).

De acordo com Thomas Szasz (1971), a natureza da "doença mental" é o problema central da psiquiatria. No seu livro “A fabricação da loucura” (1971), Szasz reconstrói como a doença mental surgiu e como ela funciona. $\mathrm{O}$ conceito de doença mental originouse do fato de que é possível agir e parecer como se fosse doente sem, contudo, ter uma doença corporal. Até a segunda metade do século XIX, conforme a leitura de Szasz, as pessoas simulavam doenças. Estas pessoas reivindicavam estarem doentes sem conseguir convencer seus médicos de que sofriam de uma doença autêntica. Por conseguinte, eram vistas como simuladoras, como se fingissem estar doentes. Freitas e Amarante (2017) 
explicam que aqueles que imitavam médicos, que diziam curar este doente fazendo medicina, eram encarados como impostores ou charlatões.

Por mais polêmicas que sejam as considerações de Szasz (1971), não se pode perder de vista que as fronteiras entre a normalidade e a patologia foram desaparecendo. Novos comportamentos e formas de sofrimento psíquico foram incorporados ao campo da assistência em saúde mental, assim como novos fenômenos começaram a se constituir como objeto da psiquiatria.

Atualmente, o paradigma biologicista da doença mental é predominante no campo da saúde mental. Seu pressuposto fundamental é o de que os transtornos ou distúrbios mentais constituídos enquanto categorias diagnósticas tem como base material supostos desequilíbrios químicos no cérebro. Tais explicações sobre o comportamento humano influenciam as leis e as políticas sociais. Assim, o paradigma biologicista tem implicações amplas e profundas para cada aspecto da vida cotidiana. Nesse sentido, a psiquiatria e as suas práticas propõe respostas simplificadoras para os comportamentos incômodos. Para tanto, a medicalização é simplificada quando se apresenta como medicação (Freitas \& Amarante, 2017).

Amarante e Cruz (2015) afirmam que se a medicina se baseia na objetivação como premissa para sua intervenção, disso decorre que ela sempre confirmou como um dado natural, biológico, os fenômenos que podem estar vinculados às condições ambientais, sociais, econômicas e políticas. Nesse jogo, a medicina passou a cumprir uma função explícita de adaptação do homem, fazendo-o aceitar a patogeneidade de toda a sua vida.

Para esclarecer um pouco mais estes pontos, é interessante retomar o pensamento de Foucault (1994) quando compreende sob a expressão "modos de subjetivação" a relação dos sujeitos com o saber poder. O conceito de modos de subjetivação segundo Foucault, refere-se a um fenômeno discursivo de natureza social que envolve a todos. Este fenômeno está presente nas narrativas e nos discursos enquanto condensações da língua e da cultura, como preferências gramaticais, padrões estéticos e morais que podem ser modificados de uma região para outra, de um tempo para outro no interior de uma mesma língua. A natureza dos modos de subjetivação é discursiva, servindo à exclusão, à diferenciação e à pertença, ou seja, à legitimação de um sujeito e de seus atos no código social. Não se pode perder de vista que os sujeitos se constituem ao se assumirem como objeto de um saber poder. 
Esse processo de ocupação pelo sujeito dos discursos e dos laços sociais podem se apresentar como sentenças que inauguram uma primeira entrevista. Silva Júnior (2018) afirma que a partir de uma auto-nomeação designada pelo diagnóstico na atualidade, podemos pensar na produção de identidades patológicas. Estas são declarações em que o sujeito se nomeia como o objeto de um saber, especificamente de um saber médico sobre o sofrimento em geral. Tais formas de auto-nomeação são transnosográficas. Neuróticos obsessivos, histéricas, bordelines, deprimidos e psicóticos frequentemente evocam um diagnóstico sobre o qual não tem qualquer dúvida e ao qual se conformam como quem descreve a cor dos cabelos. No entanto, esta auto-nomeação a partir de um quadro psiquiátrico descreve uma disfunção. Temos a nomeação de uma identidade eventualmente disfuncional, mas não uma demanda na qual esteja suposta uma responsabilidade do sujeito.

Birman (2012) aponta para uma articulação fundamental entre os processos de medicalização e psiquiatrização do social, mediados pelas neurociências e pela psicofarmacologia. Esta articulação se funda em certos modelos privilegiados de subjetivação investidos pela denominada "farmocracia" (Szasz, 1971), pela "cultura do narcisismo" (Lasch, 1983) e pela "sociedade do espetáculo" (Debord, 1997), que enfatizam a exterioridade e o autocentramento.

Para Ivan Illich (1975), a dor vivida, para se constituir em sofrimento psíquico, deve estar integrada em uma cultura. Isso se deve ao fato de a cultura fornecer um quadro que permite organizar o vivenciado, sendo condição indispensável ao desenvolvimento da denominada "arte de sofrer". A cultura confere à dor (e a outros sintomas ou doenças) uma forma da interrogação que pode ser expressa e partilhada, fornece elementos para veicular a dor, os sons, as palavras e os gestos que aliviam e permitem a comunicação, o diálogo que liga o indivíduo ao seu meio. Nesse sentido, a cultura fornece a matriz explicativa, os mitos, as lendas, o universo simbólico que explica e atribui sentido à existência da dor. Cabe pensar que a medicalização do sofrimento promove o tamponamento das indagações e o silenciamento do sujeito diante da sua dor, tendo em vista que o sujeito perde a possibilidade de tentar falar, de elaborar, de se posicionar e dar sentido para sua vivência.

Podemos fundamentar tal raciocínio desde as proposições freudianas. No texto “Mal-estar na civilização" (1930/2011,) Freud esclarece que a vida, tal como nos coube, é muito difícil, traz demasiadas dores, decepções e tarefas insolúveis, assim, para suportá- 
la não podemos dispensar o uso de paliativos. O uso de substâncias lícitas e ilícitas insurge com vistas a aplacar a angústia e com a promessa de felicidade. Neste texto, Freud postula que o sofrer ameaça-nos a partir de três lados: do próprio corpo, que fadado ao declínio e à dissolução, não podendo sequer dispensar a dor e o medo como sinais de advertência; do mundo externo, que pode se abater sobre nós com forças poderosíssimas, inexoráveis e destruidoras; e, por fim, das relações com os outros seres humanos. O sofrimento que se origina desta última fonte é experimentado mais dolorosamente do que qualquer outro tipo de sofrimento.

Ao transpor a problemática do mal-estar para a atualidade, Birman (2012) assinala que a psicanálise se encontra em crise na contemporaneidade. Esta crise não se deve exclusivamente as novas formas de subjetivação forjadas na atualidade, mas a certa perda de poder crítico da comunidade psicanalítica engendrada por certo fundamentalismo da comunidade analítica. Para o autor, a tragédia da servidão na psicanálise se articula intimamente ao esquecimento da presença do corpo na experiência do sujeito.

De outro modo, uma parcela substantiva da comunidade analítica se esqueceu de que a subjetividade sofrente tem um corpo que é justamente onde a dor se enraíza. Este esquecimento teria de certo modo entregado para a medicina e para a psiquiatria a inglória tarefa de cuidar do corpo. Em contrapartida, a psicanálise teria ficado com a parte nobre da subjetividade, o psiquismo, a versão cientificista da alma. Neste modelo que opôs corpo e psiquismo, grande parte do mal-estar contemporâneo ficaria fora da modalidade psicanalítica de escuta. Por isso, conferir ao corpo e ao afeto um lugar crucial na leitura da subjetividade é também considerar que a prática analítica não é apenas uma escuta do psiquismo, mas uma modalidade de ação (Birman, 2012).

Nota-se uma perda significativa de espaço do discurso psicanalítico concomitantemente à expansão intensa do discurso medicalizante.

\section{Corpo, sofrimento e medicalização}

De acordo com Fortes (2010), na clínica de hoje podemos notar um aumento da incidência de sintomas que se despontam no corpo sem que o paciente apresente um conflito psíquico. Para a autora, essa configuração sintomática pode ser aproximada do que Freud denominou em 1895 de "neurose atual". No referido manuscrito, Freud considera que a angústia provém de um acúmulo de excitações de origem somática. A 
excitação sexual somática é produzida concomitantemente com um decréscimo da participação do psiquismo nos mecanismos da sexualidade.

Nesse sentido, Freud (1895/1976) sinaliza a ocorrência de uma baixa de libido paralela ao acúmulo de excitação corporal, circunscrevendo a libido ao âmbito do psiquismo e concebendo a angústia como resultante do excesso de excitação provindo da dimensão corporal. Na neurose atual, concebida como sendo "puramente somática", há uma intensa descarga de angústia, porém a via de elaboração psíquica encontra-se inoperante. Ocorre um desvio da sobrecarga da excitação somática para outros canais que oferecem maior possibilidade de descarga do que a via psíquica.

Fernandes (2001) sublinha a importância do corpo nos dias de hoje, utilizando como argumento tanto um crescente número de pesquisas abordando direta ou indiretamente questões ligadas ao corpo, como a presença na clínica de um aumento considerável de demandas de análise que passam por ele. O corpo tomou a frente da cena, constituindo-se como fonte primordial de sofrimento, frustração, insatisfação e, por fim, impedimento à potência fálico-narcísica. De acordo com a autora, o corpo passou a ser veículo ou meio de expressão da dor e do sofrimento. Um sofrimento que parece encontrar dificuldade para se manifestar em termos psíquicos.

A emergência de novos sintomas que são frequentemente submetidos à intervenções medicalizantes e o surgimento de novas formas de sofrimento, denotam a submissão completa do corpo, por exemplo: os variados tipos de transtornos alimentares, a compulsão para comprar, para trabalhar, as incessantes intervenções cirúrgicas de modelagem do corpo, a sexualidade compulsiva, o horror ao envelhecimento, a busca patológica da saúde ou, ao contrário, um esquecimento patológico do corpo. Estas novas imagens evocadas pelas formas clínicas atuais parecem inventar, ou reinventar com maestria, novas sintomatologias para a velha dimensão do sofrimento humano. Ora, se a psicanálise pode ainda se definir como a arte da escuta do sofrimento humano, pode-se pensar que esse sofrimento reclama novas formas de apresentação, cumprindo sempre a mesma exigência de se fazer escutar (Fernandes, 2001).

Diferentemente da medicina que visa extirpar a dor e o sofrimento, a psicanálise embora considere o sofrimento do sujeito como condição fundamental para sua entrada em análise, ela não se contenta que seu objetivo seja reduzido à eliminação da dor .

Pontalis (2005) pontua que a vivência da dor e do sofrimento se dá no interior de um "eu-corpo". Diferentemente do que acontece com a necessidade de satisfação, no caso 
da dor, não há metáfora, ou seja, uma criação de sentido, mas a analogia que corresponde à transferência direta de um registro para o outro. São utilizadas as mesmas palavras, são invocados os mesmos mecanismos. Como se, com a dor, o corpo se transformasse em psique e a psique em corpo. Para esse "eu-corpo" ou "corpo psíquico", a relação continente-conteúdo prevalece, quer se trate de dor física ou psíquica.

As pessoas têm procurado cada vez mais os médicos, clínicos e psiquiatras, quando são acometidas por algum mal-estar no registro corporal. Seguindo o paradigma atual, é mais admissível implementar intervenções médicas sobre o corpo do que buscar medidas que possam pensa-lo e medicar no limite do necessário, evitando assim a medicalização. Esses médicos recebem e assumem grande parte das demandas dos pacientes diante do sofrimento psíquico. Entretanto, com a prática médica assumindo cada vez mais uma versão técnica-mercadológica, o clínico não dispõe de tempo para acolher psiquicamente o paciente, apenas tenta suavizar o desamparo através de uma medicalização ostensiva. As consultas são cada vez mais rápidas e a relação médicopaciente tornou-se esvaziada, salvo raras exceções. O espaço de acolhimento psíquico e escuta vem sendo solapado por uma lógica de mercado onde tempo é dinheiro.

\section{O sintoma}

Diferentemente do sintoma médico, o sintoma psicanalítico comporta especificidades que conferem a ele o estatuto de porta-voz da verdade do sujeito. Nesse sentido, Rudge (1998) esclarece que o saber analítico é um instrumento construído por Freud para interrogar a lógica inconsciente subjacente a um sintoma, ou seja, aquilo que incomoda e que causa certo dano ao sujeito que dele padece.

A psicanálise valoriza principalmente o conteúdo do sintoma, na medida em que diz respeito à experiência do sujeito, ou seja, o sintoma tem um sentido e uma significação. A partir desse pressuposto, o propósito da psicanálise seria, num primeiro momento, desvendar o sentido do sintoma (Freud, 1915/2015).

De acordo com Freud (1926/2014), o sintoma indica a existência de um processo patológico, entretanto este é um indício e substituto de uma satisfação pulsional que não aconteceu tendo como consequência o processo de recalque. Ou seja, o sintoma psicanalítico se origina do impulso pulsional prejudicado pelo recalque.

Quinet (2000) explica que assim como na medicina, na psicanálise o sintoma é um significante, porém não com o significado patológico. Para a psicanálise o sintoma 
não remete a uma doença que tenha algum substrato anatomopatológico. O sintoma para a psicanálise não revela a verdade de uma doença orgânica, pois opera em outro registro ainda que referido ao corpo. No entanto, o sintoma psicanalítico revela a verdade do sujeito do inconsciente. O sintoma é o lugar do sofrimento que também proporciona satisfação ao neurótico sem que ele saiba. Em última instância, o sintoma remete a uma modalidade de gozo, é um destino pulsional que se desvela na análise como decifração inconsciente.

Pensamos que a clínica e o ato clínico podem se configurar tanto como uma ação de tamponamento da dimensão subjetiva do sofrimento ou como tentativa de abrir esta dimensão para o sujeito. Nossa compreensão vai ao encontro do que propõe Tenório (2000) quando afirma que desmedicalizar significa incluir o sujeito, convidando - o a dirigir sua atenção para sua implicação naquilo de que se queixa, convidá-lo ainda a se interessar pela dimensão subjetiva daquilo que o acomete. Não se pode desconsiderar a historicidade existencial do sintoma, posto que este é intimamente articulado à existência particular da qual o sujeito é portador.

Se, por um lado, o sintoma médico se ancora e tem origem na materialidade biológica sobre a qual incidem as intervenções, por outro, a clínica psicanalítica, desde a descoberta do inconsciente por Freud, comporta uma especificidade distante do enfoque medicalizante, em especial, no que tange ao sintoma.

Observamos um abandono crescente da descrição causal e de sentido dos sintomas apresentados pelo sujeito em benefício de uma noção em que os sintomas são reconhecidos como manifestações de desordem da bioquímica cerebral. Entretanto, conforme Lacan (1966), se o discurso médico-científico reduz o sujeito a um organismo, a um corpo, cabe à psicanálise reintroduzir o Nome-do-Pai na consideração científica. A inclusão do significante do Nome-do-Pai no Outro marca a entrada do sujeito na ordem simbólica, permite a inauguração da cadeia do significante no sujeito do inconsciente. A ausência desse significante, que foi incansavelmente estudado por Lacan, pode desencadear tanto a psicose quanto sintomas ou estados mórbidos.

\section{O diagnóstico}

Um aspecto importante no que se refere à desmedicalização é a questão do diagnóstico. Vertzman, Herzog e Pinheiro (2010) destacam algumas distinções cruciais existentes entre as ferramentas diagnósticas utilizadas pela psiquiatria e a clínica 
psicanalítica. O diagnóstico psiquiátrico lança mão de elementos descritivos observacionais para compor sua grade nosológica. Para tanto, a dimensão da subjetividade se configura como um obstáculo a ser superado e combatido com vistas a atingir a objetividade na relação entre o indivíduo e suas formas de adoecer. Este tipo de diagnóstico se baseia, principalmente, na observação de sinais e sintomas apresentados pelo paciente.

Para Quinet (2000), o sintoma em medicina é um signo contingente que representa a doença, ou seja, a doença como algo da órbita do invisível é tornada transparente pela via do sintoma. O sintoma para a medicina representa a patologia e se opõe ao estado de saúde.

No sentido oposto, o diagnóstico psicanalítico ajuda tanto a localizar o sujeito na estrutura como na condução do tratamento. Este diagnóstico se assenta na experiência singular de sofrimento e busca articular aspectos da vivência subjetiva, como: características do discurso, expressões afetivas, responsabilidade ética por intenções e posições diante do desejo, entre outros. No entanto, uma diferença essencial marca fortemente a distinção entre esses dois campos: ao contrário do diagnóstico psiquiátrico, o diagnóstico psicanalítico é realizado sob transferência (Vertzman, Herzog e Pinheiro, 2010).

O psicanalista faz uso de uma hipótese diagnóstica como bússola inicial que só será confirmada ou rechaçada, posteriormente, sob transferência. Compreendemos que a transferência é a presentificação da estrutura na relação analítica, especificamente, de acordo com Lacan (1960), a transferência é a mola mestra do tratamento analítico.

O crescimento vertiginoso de categorias diagnósticas e a presença massiva de descrições de transtornos psiquiátricos fez com que Whitaker (2017) constatasse uma epidemia diagnóstica. A ação desses fatores teve por consequência a perda da noção de sentido/significado dos sintomas e dos sofrimentos. O diagnóstico psiquiátrico comporta uma função que antagoniza com a perspectiva psicanalítica. Se, para a psiquiatria, o diagnóstico nomeia a relação entre o indivíduo e o sofrimento, bem como estabelece um caráter de previsibilidade no que se refere ao curso da patologia. Para a psicanálise, de outro modo, o diagnóstico é pensado em seu aspecto estrutural e dinâmico, o que não deve produzir um saber fechado e generalizado sobre o sofrimento do sujeito.

$\mathrm{Na}$ psiquiatria mais restrita ao paradigma médico, o diagnóstico se resume a um ato de observar corretamente sinais e sintomas e, a partir do saber médico, atribuir a este 
o seu verdadeiro significado disponível na nosografia. Nesse paradigma, o sintoma é como um significante que espera do seu "verdadeiro" significado. Um significado universal, fixo, não-particular daquele sujeito, uma vez que disponível no "tesouro semiológico" do médico. Nota-se o efeito conclusivo, de fechamento, conferido ao diagnóstico. Diante de determinados sinais e/ou sintomas, o médico "completa" o par atribuindo o verdadeiro significado. O desafio que se apresenta consiste em interrogar de modo a fazer do sintoma questão, manejando-o segundo um endereçamento. Não basta que o sujeito se queixe de um sintoma. É preciso que essa queixa se transforme numa demanda endereçada àquele analista e que o sintoma passe do estatuto de resposta para $o$ estatuto de questão para o sujeito, que poderá então ser instigado a decifrá-lo. O desafio consiste em articular o sujeito com o seu sintoma, operando a partir de um lugar transferencial nessa passagem.

Em uma medicina capturada pela lógica de mercado, não há tempo nem espaço para o clínico acolher psiquicamente os pacientes em sofrimento, porém tentam suavizar o desamparo destes por meio da medicalização dos seus sintomas. A prescrição massiva de psicotrópicos e antidepressivos solapou a escuta atenta das queixas, corroborando o processo de medicalização e medicamentalização (Birman, 2012).

\section{Considerações finais}

$\mathrm{Na}$ história recente nos vemos assolados pelo fenômeno da medicalização. Uma cultura ostensivamente medicalizante progride progressivamente, tendo seus efeitos no tratamento e na representação do sofrimento psíquico. Nessa conjuntura, o autodiagnóstico se transformou em uma peça-chave que nomeia e marca a relação entre o indivíduo e o sofrimento. A multiplicação de diagnósticos psiquiátricos a partir das descrições diagnósticas presentes nos manuais estabelece as bases biológicas do sofrimento psíquico, mesmo quando estes se consideram ateóricos. Outro fator relevante cujo efeito potencializa a medicalização é o esvaziamento da relação médico-paciente. Esta relação que, anteriormente, se configurava como um espaço de acolhimento e escuta, era primordial para a constituição de uma ética do cuidado.

Para compreender melhor esta questão, torna-se primordial que se estabeleça a distinção entre a medicalização da angústia, o tratamento de patologias e a otimização de habilidades hipervalorizadas pela sociedade contemporânea. 
O discurso veiculado pela psiquiatria biológica ou neuropsiquiatria descreve essencialmente os fenômenos humanos em termos de um funcionamento orgânico manipulável. No entanto, este discurso também estimula o uso generalizado de psicofármacos, expondo a artificialização do corpo e colocando em questão as fronteiras entre a natureza e a cultura.

Cada vez mais a medicina passou a intervir na saúde dos indivíduos que não estão doentes, mas demandam ajuda farmacológica para lidar com as "dificuldades da existência". As pessoas estão recorrendo aos medicamentos para suportar as pressões e os sofrimentos gerados pela vida.

A ação combinada desses fatores teve por consequência a perda da noção de sentido e significado dos sintomas e dos sofrimentos, tão relevantes para a psicanálise. Assim, torna-se imprescindível conferir ao corpo e ao afeto um lugar crucial na leitura da subjetividade e considerar que a prática analítica não é apenas uma escuta do psiquismo, mas uma modalidade ética de ação.

\section{Referências}

Aguiar, A. (2004). A psiquiatria no divã. Rio de Janeiro: Reluma Dumará.

Amarante, P., \& Cruz, L. (2015). Saúde mental, formação e crítica. Rio de Janeiro: Laps.

Birman, J. (2012). O sujeito na contemporaneidade. Rio de Janeiro: Civilização brasileira.

Birman, J. (2012). Mal-estar na atualidade: a psicanálise e as novas formas de subjetivação. Rio de Janeiro: Civilização brasileira.

Birman, J. (2018) Genealogia da clínica. Revista Latinoamericana de Psicopatologia Fundamental, 21 ( 3), 442-464.

Brandão, E. (2012) Sexualidade e aliança na contemporaneidade: nem Édipo, nem barbárie. 2. Ed. Curitiba: Juruá.

Caponi, S. (2012). Loucos e degenerados: uma genealogia da psiquiatria ampliada. Rio de Janeiro: Editora FIOCRUZ.

Guarido, R. (2007). A medicalização do sofrimento psíquico: considerações sobre o discurso psiquiátrico e seus efeitos na educação. Educação e pesquisa -USP, São Paulo: USP, 33 (1), 151-161. 
Illich, I. (1975). A expropriação da saúde: nêmesis da medicina. São Paulo: Nova Fronteira.

Fernandes, M. (2001). As formas corporais do sofrimento: a imagem da hipocondria. Rev. Latinoamericana de Psicopatologia Fundamental, IV, 4, 61-80.

Foucault, M. (1994). Dits et écrits IV. Paris: Gallimard.

Freud, S. (1976). Sobre os critérios para destacar da neurastenia uma síndrome particular intitulada neurose de angústia. Edição Standard brasileira das obras completas de Freud. V. III. Rio de Janeiro: Imago. (Trabalho original publicado em 1895)

Freud, S. (2015). A pulsão e seus destinos. Tradução: Pedro Heliodoro Tavares. Belo Horizonte: Autêntica Editora (Trabalho original publicado em 1915).

Freud, S. (2011). O mal-estar na civilização. V. XXI. São Paulo: Penguin Classics Companhia das Letras. (Trabalho original publicado em 1930).

Freitas, F., \& Amarante, P. (2017). Medicalização em Psiquiatria. Rio de Janeiro: Editora Fiocruz.

Kaufmann, P. (1966). Dicionário enciclopédico de psicanálise. Rio de Janeiro : Jorge Zahar, 1996.

Lacan, J. (1960). La transferencia. Editorial Paidós.

Lacan, J. D'une question préliminaire à tout traitement possible de la psychose (195758). In: Lacan, J. Écrits. Paris: Seuil, 1966.

Lasch, Christopher. (1983). A cultura do narcisismo. Rio de Janeiro, RJ: Imago.

Lima, R. C. (2005). Somos todos desatentos?: o TDA/H e a construção das bioidentidades. Rio de Janeiro: Relumé Dumará.

Lipovetsky, G. (1989). O império do efêmero. São Paulo: Companhia das Letras.

Pontalis, J.-B. (2005). Entre o sonho e a dor. São Paulo: Editora Idéias \& Letras.

Rudge, A. M. (1998). Pulsão e linguagem: esboço de uma concepção psicanalítica do ato. Rio de Janeiro: Jorge Zahar.

Szasz, T. (1971). A fabricação da loucura. Rio de Janeiro: Zahar Editores.

Silva Júnior, N. (2018). O mal estar no sofrimento e a necessidade de sua revisão pela psicanálise. In: SAFATLE, Vladimir; SILVA JUNIOR, Nelson; DUNKER, Christian (Orgs.). Patologias do social. Belo Horizonte: Autêntica editora.

Tenório, F. (2000). Desmedicalizar e subjetivar: A especificidade da clínica da recepção. Cadernos IPUB, 6 (17), 79-91. 
Tenório, F. (2016). Psicose e esquizofrenia: efeitos das mudanças nas classificações psiquiátricas sobre a abordagem clínica e teórica das doenças mentais. História, Ciências, Saúde-Manguinhos, 23 (4), 941-963.

Quinet, A. (2000). A descoberta do inconsciente. Rio de Janeiro: Zahar.

Whitaker, R. (2017). A anatomia de uma epidemia. Rio de Janeiro: Editora Fiocruz. 